\title{
INFÂNCIA, TRABALHO E LÚDICO NO CONTEXTO DA AGRICULTURA FAMILIAR FUMAGEIRA
}

Recebido em: 15/10/2013

Aceito em: 03/05/2014

Elizara Carolina Marin

Andressa Aita Ivo

Centro de Educação Física e Desportos - CEFD

Universidade Federal de Santa Maria - UFSM

Santa Maria - RS - Brasil

Giovani Frizzo

Escola Superior de Educação Física - ESEF

Universidade Federal de Pelotas - UFPel

Pelotas - RS - Brasil

Joel Orlando Bevilaqua Marin Centro de Ciências Rurais

Universidade Federal de Santa Maria - UFSM

Santa Maria - RS - Brasil

RESUMO: $O$ presente artigo trata das relações entre o trabalho e a dimensão lúdica durante a infância na agricultura familiar fumageira no município de Agudo-RS, a partir do viés do adulto. Para tanto, o levantamento de dados foi realizado através de entrevistas, as quais foram realizadas com 27 agricultores, que se dedicam à agricultura familiar, e que têm filhos menores de 18 anos. Discute-se, também, a categoria trabalho, a partir da distinção entre a exploração do trabalho infantil e do trabalho educativo na infância e o deslocamento do processo educativo e lúdico da família e da vizinhança para a escola, o que pode levar à própria negação da agricultura familiar como forma social de vida.

PALAVRAS CHAVE: Trabalho de menores. Jogos e brinquedos. Agricultura.

\section{CHILDHOOD, WORK AND PLAYFUL IN THE CONTEXT OF TOBACCO FAMILY FARMING}

ABSTRACT: This article deals with the relationship between work and the playful dimension in childhood in tobacco family farming in the city of Agudo-RS from the bias of the adult. For this, data collection was conducted through questionnaires and interviews with 27 male and female family farmers who have children under 18 years old. Discusses the work category from the distinction between the exploitation of child labor and educational work in childhood and the displacement of the educational and playful process 
of the family and neighborhood to school, which can lead to negation of family farming as a form of social life.

KEYWORDS: Child Labor. Play and Playthings. Agriculture.

\section{Introdução}

A infância é construção social, variável no tempo e no espaço. Os modos de vivê-la, percebê-la e representá-la transformaram-se ao longo da história e diferenciaram-se entre os grupos sociais. Segundo Ariès (1981), as concepções modernas de infância, como uma fase específica da vida, dedicada aos estudos e à preparação para o futuro, foram construídas a partir da emergência da burguesia europeia. A partir desse processo social, houve a necessidade de fortalecimento da família para proteger as crianças, bem como de uma maior intervenção da sociedade e do Estado a fim de oferecer a elas escolarização, assistência e proteção. Além disso, as crianças deixaram de trabalhar para que pudessem dedicar-se aos estudos e às brincadeiras.

Num movimento lento e gradual, mas não sem contradições e conflitos, as crianças passaram a ser socialmente percebidas como pessoas em condições especiais de desenvolvimento, sujeitos de direitos próprios, com direitos de capacitação adequada e necessidades de proteção diferenciada, específica e integral. Construídas e positivadas nas legislações dos países desenvolvidos, tais concepções de infância foram universalizadas a partir do século XX, especialmente após a Segunda Guerra Mundial, pela atuação incisiva dos organismos internacionais como a Organização das Nações Unidas (ONU), o Fundo das Nações Unidas para a Infância (UNICEF) e a Organização Internacional do Trabalho (OIT). Por meio da proposição de um conjunto de doutrinas e de políticas públicas, estas 
organizações internacionais procuram difundir novas concepções de infância, direitos da criança e aparato de regulação do trabalho infantil. Desta maneira, concepções de infância e adolescência, socialmente construídas em países desenvolvidos, passaram a influenciar a legislação nacional, no sentido de preservar as crianças e os adolescentes do uso predatório e indiscriminado de sua força de trabalho. A infância passou a ser entendida como idade da vida em que deve ser preservada do trabalho, para possibilitar-lhes o desenvolvimento físico e intelectual. A adolescência, enquanto fase transitória entre a infância e a vida adulta, também necessitava de condições especiais para garantir o pleno desenvolvimento físico-intelectual e a preparação para a entrada no mundo do trabalho. (MARIN, MARIN, 2008)

Mas, na realidade social, existem diferentes maneiras de viver e de representar a infância. As instituições encarregadas pela socialização, bem como os significados e representações sociais criados sobre a infância, sofrem variações de uma sociedade para outra e dentro de uma mesma sociedade, ao longo dos processos históricos. Assim, para compreender a infância, é necessário compreender os contextos econômicos, sociais e culturais em que as crianças e suas famílias vivem e as transformações que se processam em cada sociedade.

No espaço agrário contemporâneo, especialmente no âmbito da agricultura familiar, foco desta pesquisa, a infância vem sofrendo profundas transformações nas formas de socialização, em face da ampliação dos direitos das crianças e adolescentes e da valorização da instituição escolar. Por agricultura familiar, entende-se, à luz de Schneider (2005), uma forma social de vida que compreende a posse ou propriedade de terra (geralmente pequena 
dimensão), o trabalho, realizado majoritariamente pelo grupo de parentesco, e a produção agrícola orientada para autoconsumo e comercialização de excedentes mercantis.

Neste artigo, prioriza-se a análise das relações entre a infância, o trabalho e a dimensão lúdica de agricultores familiares que se dedicam à produção de tabaco no município de Agudo, localizado na região central do Estado do $\mathrm{RS}^{1}$. A opção por realizar a pesquisa neste município partiu da constatação de que pertence a uma das maiores regiões produtoras de fumo no Brasil (significa que a renda familiar advém quase na totalidade da cultura do fumo) e pelo fato de que os trabalhos realizados nestas lavouras passaram a ser tipificados como trabalho infantil, portanto, condenados legalmente. A promulgação do Decreto n. 6.481, de 12 de julho de 2008 - que regulamenta o terceiro e quarto artigos da Convenção 182 da Organização Internacional do Trabalho (OIT) - inseriu o trabalho no fumo na lista das piores formas de trabalho infantil, por suas possíveis repercussões sobre a saúde e escolarização de crianças e adolescentes.

Os dados oficiais, por sua vez, indicavam taxas elevadas de exploração de trabalho de crianças e adolescentes. A Organização Internacional do Trabalho (OIT) estimou que, no ano 2000, existiam em torno de 211 milhões de crianças entre 5 e 14 anos trabalhando no mundo, as maiores porcentagens foram observadas na Ásia, África e América Latina (KASSOUF, 2007). No Brasil, dados da Pesquisa Nacional por Amostra de Domicílios (PNAD) de 2005 mostraram que existem quase três milhões de crianças e jovens de cinco a 15 anos trabalhando (7,8\% do total nessa faixa etária) (KASSOUF, 2007). Ainda de acordo com a PNAD de 2001 (IBGE, 2003), no RS existiam 200 mil crianças e jovens entre 5 e 17

\footnotetext{
${ }^{1}$ Este artigo é parte de pesquisa mais ampla aprovada e financiada pelo Conselho Nacional de Desenvolvimento Científico e Tecnológico (CNPq).
} 
anos que trabalhavam, representando aproximadamente $10 \%$ do total desta faixa etária. Apontava ainda que $31,8 \%$ das crianças e jovens que trabalhavam em atividades agrícolas exerciam atividade de risco no setor agrícola ${ }^{2}$ carecendo, portanto, de estudos que se proponham a dialogar com as famílias sobre a infância e a compreender a questão do que passou a ser tipificado como trabalho infantil.

A "Convenção-Quadro para Controle do Tabaco", considerada o primeiro tratado internacional de saúde pública, proposta pela Organização Mundial de Saúde (OMS) e negociada por aproximadamente duzentos países entre os anos de 1990 e 2003, ratificou, em novembro de 2005, os problemas oriundos da exploração do trabalho infantil no cultivo do fumo que ganharam maior notoriedade. Em linhas gerais, a Convenção Quadro procura estabelecer medidas restritivas ao consumo, comercialização e produção de derivados do tabaco, por entender que o tabagismo é uma epidemia de escala mundial. O Brasil, como signatário da Convenção Quadro e o maior exportador de tabaco, procurou estabelecer medidas para reduzir a produção de tabaco, por meio do Programa Nacional de Diversificação em Áreas Cultivadas com Tabaco, com propósito de criar novas possibilidades produtivas aos agricultores fumicultores. (MARIN et al, 2011)

Esses dados são agravados quando se identifica que, na produção do fumo, os agrotóxicos utilizados são uns dos principais fatores de risco para suicídios, além de diversos outros distúrbios mentais. Os estudos realizados por Falk et al (1995) ${ }^{3}$, no município de Venâncio Aires, cidade do interior do RS que também tem predominância da

2 A PNAD considera que as atividades de risco no setor agrícola é o trabalho nas plantações de sisal, algodão, cana-de-açúcar, café, fumo, criação de animais e corte de árvores (IBGE, 2003).

$3 \mathrm{O}$ relatório das investigações destes autores está presente no "Relatório Azul", documento publicado anualmente pela Comissão de Cidadania e Direitos Humanos da Assembleia Legislativa do Rio Grande do Sul 
produção de fumo em suas atividades econômicas prioritárias, aponta que os índices de suicídios de agricultores são elevados.

No RS, o fumo é produzido fundamentalmente por agricultores familiares. Nesta forma de produção, todos os membros das famílias se envolvem no trabalho, inclusive as crianças e adolescentes.

\section{Procedimentos metodológicos}

Para dar conta de compreender o sentido do trabalho na formação humana, em especial da criança, e as relações entre o lúdico e a infância no contexto da agricultura familiar fumageira, foi realizado um estudo de caso no município de Agudo, envolvendo uma amostragem não probabilística de 27 agricultores e agricultoras familiares, que necessariamente produzem fumo e que têm filhos com menos 18 anos. Cerca de $60 \%$ das famílias entrevistadas são chefiadas por adultos entre 41 e 50 anos de idade e $30 \%$ das famílias encontram-se na faixa dos 31 até os 40 anos. O número de integrantes das famílias da amostragem não é elevado: cerca de $29,6 \%$ são constituídas por apenas três pessoas, $33,3 \%$ por quatro pessoas, $18,5 \%$ por cinco pessoas, $11,1 \%$ por seis e apenas $7,4 \%$ por sete pessoas. O número total de crianças pertencentes às famílias que compõem a amostragem é de 29. As entrevistas foram dirigidas aos pais das crianças, seguindo um roteiro semiestruturado, constituído de questões abertas ligadas à problemática da pesquisa.

O artigo trata, de modo articulado, duas questões: o trabalho na formação do ser humano, seu caráter ontológico, enquanto atividade humana produtiva, e histórico, como subsunção ao capital no atual modo de produção da existência, em especial, das distinções entre a exploração do trabalho infantil e do trabalho educativo durante a infância; e as 
relações entre infância, trabalho e lúdico no contexto da agricultura familiar fumageira a partir do viés do adulto.

\section{O sentido do trabalho na formação humana e o trabalho infantil no cultivo de fumo}

Ao discutir-se as questões sobre o trabalho infantil, é preciso ter em conta diferentes esferas de análise, a primeira delas diz respeito ao que significa o trabalho na vida do ser

humano. É a partir de Marx (2006) que se torna possível compreender o trabalho como a mediação do ser humano com a natureza, ou seja, a forma de produzir a sua existência. Diante disso, o trabalho caracteriza-se como atividade humana produtiva, tanto em relação à natureza como em relação às demais pessoas, sendo a partir do trabalho que o ser humano se torna humano (ser social). Essa perspectiva aponta o trabalho como categoria ontológica própria do ser humano.

Ao mesmo tempo, enquanto forma de produzir a existência humana, o trabalho também adquire características próprias de cada período histórico, determinado pelo modo de produção vigente em cada época. Trata-se, aqui, do sentido histórico do trabalho que, no modo de produção capitalista, adquire caráter de trabalho alienado, explorado e estranhado ao ser humano, que é reduzido a vendedor de sua força de trabalho para garantia de sua sobrevivência. É exatamente neste processo de venda da força de trabalho que se encontra a característica alienante do trabalho subsumido ao capital. Pois, como foi afirmado anteriormente, o trabalho é atividade humana de produção da existência, que, no atual modo de produção hegemônico, o ser humano o vende a outro, qual o sentido de emancipação e humanização existente nesta forma de trabalho assalariado e explorado? 
Essa questão do trabalho subsumido ao capital pode ser exemplificada através do campo de pesquisa deste estudo: a produção de fumo na agricultura familiar. A produção moderna de fumo se dá pelo sistema de integração agroindustrial, nesse sistema de produção integrada "o pacote tecnológico das multinacionais do fumo traz a obrigatoriedade do crédito, dos insumos (fertilizantes, agrotóxicos e outros), da comercialização dirigida, bem como classifica o produto conforme os interesses momentâneos de mercado e venda compulsória" (FALK et al, 1995, p.143). Assim, "o agricultor tabacalero é submetido, juntamente com sua família e com suas organizações, aos interesses destas empresas, atrelando-os a uma total dependência e manipulação cartelizada" (FALK et al, 1995, p.143).

A produção de tabaco realizada em Agudo é altamente exigente em mão de obra. Considerando que as famílias são numericamente pequenas todos os integrantes da família somam seus esforços para a execução das atividades produtivas, compreendidas desde o plantio das sementes, transplante das mudas nas lavouras, tratos culturais das plantas até a colheita, secagem e classificação das folhas de tabaco. Dadas as condições técnicas impostas pelas agroindústrias do fumo e a necessidade de executar todas as atividades do ciclo produtivo do tabaco, crianças e adolescentes, filhos dos agricultores fumicultores, também contribuem no somatório da mão de obra, variando conforme as condições físicas, idade e sexo.

Para efeitos legais, este trabalho realizado por crianças e jovens com menos de 18 anos de idade é considerado trabalho infantil. Mas, sob a perspectiva das famílias dos agricultores fumicultores, os trabalhos executados pelas crianças no âmbito da família são considerados ajuda e meios de socialização e aprendizado para a vida. Então, nota-se a 
existência de diferentes concepções a cerca do trabalho executado pelas crianças e adolescentes no âmbito familiar.

A partir dos depoimentos orais de agricultores fumicultores, foi possível identificar a preocupação dos pais em relação ao trabalho dos filhos. A maior parte destes afirmou que as crianças não são obrigadas a trabalhar no cultivo do fumo. Executam tarefas referentes ao cuidado da propriedade familiar, seja nos serviços domésticos quanto em relação aos cuidados com o pomar, horta, tratamento dos animais, dentre outros. Nesse sentido, o trabalho realizado pelas crianças e jovens são, predominantemente, referentes ao trabalho que produz e organiza a vida, com sentido educativo e de sobrevivência, como expressa o depoimento de um dos agricultores entrevistados:

Ele [seu filho] sempre foi aprendendo. A gente nunca chegou e deu uma responsabilidade para ele. Às vezes, tem dia que a gente diz que tal hora tem que buscar lenha, fechar os terneiros. Mas, coisas aqui perto e não pegar os bois na lavoura ou ir na roça sozinho. Ele hoje acompanha, mas não tem responsabilidade (fragmento de entrevista).

Os pais tanto relatam que não há obrigatoriedade do trabalho dos filhos quanto afirmam a existência do mesmo enquanto "ajuda" aos afazeres cotidianos, inclusive esboçando o caráter educativo, conforme enunciação abaixo referente ao trabalho que consideram que os filhos podem realizar:

Fazer alguma coisa como na cozinha, varrer a casa, alguma coisa que ela [filha] tenha condições de fazer. Com as suas condições de força, de idade, porque, no futuro, ela pode passar isso para família, para os filhos dela. O que ela aprendeu, ela pode um dia passar. Assim como o que eu aprendi, aos poucos eu vou passando para ela o que eu aprendi, a educação que eu recebi de casa (fragmento de entrevista). 
Embora o trabalho das crianças seja considerado ajuda pelos pais e mães, há contradições em relação ao grau de exigência de tarefas que são colocadas para as crianças em determinadas épocas da produção do tabaco. No período da colheita, de maneira especial, realizado entre dezembro e janeiro, época do ano de muito calor e de maior demanda de mão de obra, as crianças e adolescentes também são envolvidas com o trabalho na lavoura. O relato a seguir, sobre o trabalho que consideram que os filhos podem realizar no fumo, é elucidativo:

Tudo ele prejudica. Mas alguma coisa e outra eles ajudam. Pra colher às vezes. É pesado, mas é no ritmo deles. São trabalhos como atar debaixo do galpão. Mas às vezes só depois da aula de tardezinha. Porque eles não podem faltar à aula pra ajudar na colheita. A gente pega peão por fora pra ajudar. Mas na capina assim também, mas isso nem a gente faz ou faz pouco. No plantio a gente planta com máquina e não envolve muitas pessoas (fragmento de entrevista).

Sob a perspectiva legal, o trabalho infantil também se caracteriza quando a criança ou adolescente são utilizados para a substituição de mão de obra adulta. De acordo com a legislação vigente, menores de 18 anos não podem trabalhar com a cultura do tabaco, ainda que seja com caráter educativo, pois neste tipo de produção há uma elevada utilização de agrotóxicos, além de ser um "trabalho pesado" (caracterizado assim pelos próprios agricultores), expondo, portanto, as crianças e jovens às atividades consideradas de risco à saúde. Mas, os pais entrevistados garantem que o tempo das crianças e jovens são divididos entre o trabalho, a escola e a vivência lúdica. Dessa maneira, entendem que direito aos estudos e às brincadeiras são assegurados aos próprios filhos. Outros fatores importantes atribuídos ao trabalho desde a infância são a ocupação do tempo com aspectos significativos da vida familiar, a apropriação do saber-fazer e o desenvolvimento de 
sentimentos de responsabilidade e de amor ao local em que vivem, como pode ser elucidado a seguir:

No fumo eles têm trabalhado sim. Mas em primeiro lugar é o estudo. Os demais serviços eles fazem mais. Fazem fogo, botam a boia em cima do fogão. Para que pelo menos a gente chegue e pelo menos já tem fogo no fogão. Água bem limpa, casa limpa [...] Eu prefiro que eles se ocupem pra que eles não fiquem na rua. Esses trabalhinhos é uma maneira de manter eles aqui pra que eles se apeguem a propriedade. Fiquem aqui. Eles têm que aprender alguma coisa (fragmento de entrevista).

Neste fragmento identificam-se duas preocupações significativas das famílias em relação às crianças: uma em relação aos estudos e à escola; e outra em relação à permanência no campo quando chegar à vida adulta. É frequente nos depoimentos o fato de que as crianças e jovens não veem seu futuro vinculado ao trabalho na terra, como seus pais, gerando uma preocupação em relação ao futuro dos filhos.

Essa é uma questão um tanto ambígua, pois ao mesmo tempo em que os pais demonstram preocupação com o fato de que o trabalho na lavoura não terá continuidade por parte de seus filhos e filhas, também é possível identificar que alguns pais não querem que eles vivam do trabalho pesado do cultivo do tabaco, preferindo a continuidade dos processos de escolarização, a fim de possibilitar um futuro melhor, vinculado à cidade e ao trabalho urbano:

$\mathrm{Eu}$ queria que eles se formassem. Porque é muito bonito uma formatura. Eu queria que eles se formassem em alguma coisa pelo menos (fragmento de entrevista).

[...] se ela não vai agora na roça, depois ela jamais iria na roça, no fim das coisas. Foi isso que eu disse hoje, que quando ela tiver na idade, uns dezessete anos mais ou menos, aí ela vai sair também [...] Minha mãe, a avó deles também está na 
cidade. Já chamaram pra lá e gostaram da cidade. Tem os colegas, melhor, fica por lá. Na roça não tem colega essas coisas (fragmento de entrevista).

Segundo Marin et al (2012, p. 776), ainda que "o trabalho caracteriza-se, no imaginário dos agricultores de Agudo, como um processo educativo pelo qual é transmitido o modo de vida local e os conhecimentos necessários para tornar-se futuro agricultor ou agricultora", foi possível observar que, com o passar das gerações, o trabalho tem assumido cada vez menos importância na socialização dos filhos dos agricultores. Em contrapartida, a instituição escolar torna-se central na formação das novas gerações, em virtude da obrigatoriedade da frequência escolar e da percepção de que estudos escolares são uma alternativa para que os filhos tenham uma vida melhor do que a deles. Percebem que os estudos prolongados constituem uma possibilidade de mudança e ascensão social. Portanto, nos contextos mais recentes, a inserção das crianças na agricultura familiar tem sido geralmente restringida às atividades domésticas, aos trabalhos nos arredores da propriedade, aos cuidados dos irmãos mais novos, a auxílios nos trabalhos agrícolas, sob supervisão dos adultos:

[...] nós aqui em casa, não queremos para o nosso filho o que nós passamos na nossa época. Por mais que ele às vezes vai com nós, tem alguém responsável junto. Se ele vai na lavoura e ajuda a carregar um pouco de fumo eu exijo que ele bote bota, chapéu, manga comprida. Que se proteja. É muito diferente da nossa época. Eu com a idade dele tinha que ajudar o pai a passar veneno e eu não deixo ele pegar uma máquina de passar veneno de jeito nenhum (fragmento de entrevista).

Já nas lembranças da infância dos próprios agricultores, o trabalho assumia espaço central: 
Sempre com meu pai. Era bem mais rigoroso. A partir dos 7, 8 anos a gente foi direto pra lavoura, acompanhou. Vinha da aula, almoçava e de tarde fazia as tarefas, quando tinha tempo disponível. E o resto da sobra do tempo ia pra lavoura. Depois com 12 ou 13 anos aí já ia tocar os arados. Aí já fazia praticamente todo o serviço que existia. Cortava uma lenha de machado. Tenho o machado guardado até hoje e é bom o machado. Hoje meus guris nem sabem cortar de machado quanto menos agarrar uma motosserra (fragmento de entrevista).

Eu trabalhei desde os nove ou dez anos no fumo. Tinha que cuidar os outros. Nós somos em 12 irmãos. O mais velho tinha que cuidar dos outros. Tinha que trabalhar e estudar também (fragmento de entrevista).

Nós fazia o serviço pesado. No meu tempo era tudo cortado a machado. Tudo eu e minha irmã fazíamos serviço pesado. Tínha que tombar as madeiras, carregar pra cima. Nós era pequenas e fazia tudo. E nós tinha que ir, se não o laço pegava. Nós capinava com enxada. Tinha uns 7 ou 8 anos, desde que eu me lembro que nós já começamos a trabalhar. Capinava as plantas, tudo. Naquele tempo não tinha veneno né (fragmento de entrevista).

O trabalho na infância dos agricultores fumicultores fazia parte da formação ao lado da escola, espaço/tempo para o aprendizado da escrita, da leitura e das operações matemáticas. Atualmente, observa-se a maior valorização do estudo em relação ao trabalho, resultando em significativas mudanças nos processos de socialização das novas gerações no contexto da agricultura familiar.

\section{Infância, trabalho e lúdico no contexto da agricultura familiar fumageira}

Embora haja esforço para universalizar a concepção de infância como uma idade da vida em que os adultos devem garantir direitos ao desenvolvimento físico e intelectual, aos estudos e às brincadeiras, há de se considerar as especificidades dos contextos econômicos, sociais e culturais do grupo social, para compreender as relações entre trabalho, infância e lúdico. 
Nas relações sociais da agricultura familiar fumageira, os agricultores entrevistados, rememorando suas infâncias, destacam a relevância que o trabalho possuía para a formação das crianças:

\begin{abstract}
A minha infância foi assim, eu cresci e quando já podia agarrar uma enxada, eu com 5 anos já andava a cavalo pra cultivar o que o pai plantava lá, milho e cevada. Aí quando eu fiz 8 anos a minha irmã tinha 6 . Aí o pai disse assim pra mãe, eu acho que a Dalva já pode te ajudar a capinar e a outra pode andar a cavalo. Aí no outro dia eu estava com uma enxadinha com oito anos de idade. A gente ia na escola, e a gente tinha o compromisso da gente. A gente sabia que aquela choca com pinto era serviço meu, fechar aquele chiqueiro era serviço da minha irmã e encerrar terneiro era serviço daquele (fragmento de entrevista).

O pessoal valorizava muito assim: a criança naquela época tinha que aprender a trabalhar cedo. Eles não se preocupavam tanto com os estudos. [...] eu fui uma pessoa que, acho, dos 8 até os 14 anos, eu cozinhei muito. Então assim, porque a mãe estava na lavoura, isso tudo fez com que a gente fizesse outros trabalhos mais leves. E meu irmão a mesma coisa, fazia um trabalho mais leve. Mesmo assim era de manhã ou de tarde na escola e na outra parte do dia era de serviço (fragmento de entrevista).
\end{abstract}

Os relatos evidenciam a relação que os agricultores estabelecem entre a infância e o cumprimento de obrigações e deveres do trabalho para com o grupo familiar. Para eles, o período da infância não é compreendido como reinado absoluto do lúdico. Ademais, associar a infância como período de pleno "descompromisso" advém "de uma abstração da criança, que não a enxerga como integrante da sociedade concreta" (MARCELLINO,1990, p.54)

O lúdico aqui é compreendido a partir da acepção de Gomes (2004, p.145) como "expressão humana de significados da/na cultura referenciada no brincar consigo, com o outro e com o contexto" e que carrega no seu bojo as contradições sociais.

Nessa direção, o sentido de infância, apontada pelos agricultores, está intimamente relacionada às experiências vividas, as quais são muito diferentes daquelas vividas por seus 
filhos. Ao confrontarem a infância vivida por eles e a vivida pelos seus filhos, os agricultores concluem pontualmente que os filhos gozam de certos privilégios que eles nunca tiveram:

\begin{abstract}
Mudou muito. Os filhos hoje têm muita mordomia. Hoje eles não fazem nada do que nós fazíamos. Praticamente nada do quanto nós trabalhávamos. Nós trabalhávamos bastante (fragmento de entrevista).

Eu estudava. A gente ajudava os pais a trabalhar também. Que nem hoje em dia já é diferente. A gente bota os pequenos pra ajudar, às vezes. Mas é mais pra aprender. A gente na infância tinha que ajudar mais os pais porque não tinha como hoje, empregados. Ficou mais fácil. (fragmento de entrevista).
\end{abstract}

Os relatos evidenciam que a infância dos agricultores foi marcada pelo trabalho, pela imposição e obrigatoriedade, mas também pela presença do lúdico nos tempos possíveis, como, por exemplo, ao término das atividades domésticas e da lavoura e nos finais de semana. Como relata um agricultor entrevistado: "nós era em seis irmãos e seis irmãs e cada dia de meio-dia e de tardezinha nós jogava futebol. Uma hora, meia hora e nos sábado de tarde e domingo o dia inteiro" (fragmento de entrevista). Outra entrevistada destaca: "nós trabalhava, mas brincava também. Nós brincava depois na lua cheia, de noite. Nós jogava bola. Era legal" (fragmento de entrevista).

Embora o cotidiano estivesse permeado por diferentes tarefas, eles brincavam junto aos irmãos e vizinhos da mesma faixa etária. Os pais lembram que as famílias de décadas passadas eram numerosas, o que propiciava maiores possibilidades de criação de momentos e espaços de convívio familiar e comunitário, de brincadeiras e de vivências lúdicas. A carência material das famílias não permitia a compra de brinquedos, mas nem por isso deixavam de produzir seus brinquedos e diversões, valendo-se dos recursos disponíveis. A 
ausência de brinquedos prontos, industrializados e de tecnologias dava lugar à imaginação

das crianças.

Domingo tinha tempo. Domingo a gente inventava. A gente fazia aqueles carrinhos de corre cerro a baixo. A gente fazia as bolas. Pegava um saco plástico e enchia de pano e isso dava a brincadeira. Hoje a maioria das crianças, mesmo os meus aqui, por causa desses computadores ficam só ali. Mas na época isso tudo não existia e aí aos domingos a gente se juntava aquela turma de 8 ou 10 crianças e ia de um vizinho pra outro (fragmento de entrevista).

Brincar a gente brincava, mas não que nem hoje. É que assim, aquela vez não tinha brinquedos que nem hoje em dia. A gente brincava com os talos de fumo, sabugos e fazia os brinquedos pra gente. E hoje em dia não, tem que ser tudo comprado (fragmento de entrevista).

Hoje em dia não tem mais. Antigamente se aproveitava mais. A gente tinha carreta de madeira que se fazia em casa. Fazia casinha assim de madeira. Boneca a gente não conhecia, nossas bonecas eram uma pedra. Não era como hoje (fragmento de entrevista).

As crianças criavam, construíam seus próprios brinquedos, corroborando com Benjamin (1984, p.70), quando aponta que o imaginário da criança determina o brinquedo e não o contrário, "a criança quer puxar alguma coisa e torna-se cavalo, quer brincar com areia e torna-se padeiro, quer esconder-se e torna-se ladrão ou guarda”. Outra característica condiz às brincadeiras, as quais eram realizadas no campo, em áreas abertas, diferente do que acontece atualmente com a presença das tecnologias. Quando questionados sobre a infância dos seus filhos, os agricultores tecem as seguintes considerações:

Brincar, o que que ele faz. É o computador ali. Ou às vezes vai nos vizinhos, mas aí vão no computador também. Quando muito jogam uma bolinha. Não tem mais aquilo de se juntar uns quantos e ir no potreiro brincar de caçador. Brincar de esconder. Ele brincava bastante de fazer lavourinha, brincava de trator, ganhava bastante brinquedo. Então numa época no galpão ele tinha lá suas estradas, cidades inteiras, criava bastante. Hoje parou com tudo. Esse tipo de brincadeira parou lá pelos 10 anos. Lembro que eu tinha só um lampião de querozene e o pai e a mãe sentavam na frente do fogão para tomar chimarrão e eu e a minha irmã sentava na caixa de lenha e brincava com os sabugos de boizinho. Lá em baixo das laranjeiras, juntava laranjinha, brincava de bolita. Tinha que criar as 
brincadeiras. E hoje em dia está tudo muito pronto e elas não conseguem mais criar. Nós tínhamos que criar o que nós queríamos (fragmento de entrevista).

Hoje em dia ela gosta de jogar videogame, assistir televisão. Nós nem conhecemos isso. Nós jogava de pega-pega. Bolita, caçador, ovo podre. Fazia roda e largava um papelzinho atrás e o cara tinha que olhar quem era pra pegar. Tinha que correr atrás (fragmento de entrevista).

As formas de expressão lúdica, os jogos vivenciados nos seus tempos de infância são, segundo os relatos dos agricultores, desvalorizados pelos filhos. Denota que as percepções do brincar e do jogar mudaram entre as gerações de pais e filhos. Chama atenção dos pais o fascínio que os jogos de computador exercem sobre os filhos e gera desapontamento a não valorização dos jogos e brinquedos que foram significativos e envolventes em suas infâncias. O relato sobre o jogo de bolita é elucidativo:

Esses dias o pai dele tava brigando com ele que quando ele tinha treze anos ele jogava bolita. Ele tinha uma caixa grande de bolita que ele guardou se um dia ele tivesse um guri ele iria dar. Aí ele guardou e deu quando ele tinham uma certa idade, mas já tá lá tudo largado (fragmento de entrevista).

Uma vez que a sociedade contemporânea é caracterizada pela predominância das tecnologias, sobretudo digitais, e pela interação mediada pela máquina, novos modos de relações sociais e interpessoais se interpõem nos diferentes contextos, incluso no rural, que possibilita situações não vivenciadas pelos entrevistados. Cabe destacar também suas percepções em relação à escola:

Mudou muito. O meio de estudar e tudo. Hoje tá tudo diferente, mais fácil, mais moderno. Eu tinha que caminhar muito longe a pé. Não tinha transporte escolar. Hoje em dia a gurizada tem tudo mais fácil. O ônibus passa na frente de casa. Eu acho mais fácil (fragmento de entrevista).

Nós morava no cerro e dava 10,11 quilômetros e tinha que ir a pé. Nada de transporte. Hoje passa aqui na frente, é só embarcar (fragmento de entrevista). 
Nas últimas décadas, em especial, a partir de 1990, diversos programas do governo federal têm sido implementados nos municípios com o intuito de atender aos alunos do contexto rural, tais como acesso à escola facilitado pelo transporte escolar, acesso às tecnologias comunicacionais, oferta de atividades extraclasses (esportivas, de reforço, computação), entre outros. Marin et al (2012) identificaram que, de forma geral, as crianças de Agudo têm frequência regular na escola e que $81 \%$ das crianças completam o ensino médio. Com a obrigatoriedade da escolarização, a infância dos filhos dos agricultores, divide-se entre a escola e a casa com a realização de pequenas atividades domésticas:

Ele busca um pouco de pasto. Às vezes, ele vai lá e alcança fumo pra gente. Ele ajuda em tudo. Mas quando chega a hora de estuda, ele estuda. (...) eles sempre foram junto na roça. Foram acostumados. Então agora ele vai. Vai busca bergamota, sempre arruma alguma coisa pra fazer (fragmento de entrevista).

Ela mais estuda e ajuda cuidar a irmãzinha que é pequena. Mas assim, trabalho na lavoura e coisa, ela não faz (fragmento de entrevista).

Não era que nem nós. Eles não fazem nada. Nada. No fumo até hoje nunca. Bom, entrar na lavoura de fumo só trazer água às vezes, senão nunca vai. E nas férias o que faz é arrumar a cama dele e lavar a xícara do café da manhã, porque mais não faz (fragmento de entrevista).

Os pais apontam que os espaços de sociabilidade das crianças, anteriormente localizados na esfera da família e da vizinhança, atualmente encontram-se preponderantemente na escola. $\mathrm{O}$ fato de a grande maioria residir no interior do município e as casas serem distantes umas das outras, dificulta os encontros, a comunicação e a interação com outras crianças. Os relatos expressam uma mescla de ausência e solidão: 
Isso dificulta muito. Se ele quer amigos da idade dele ele tem que ir na cidade. Tem uma menina aqui perto de 10 anos. Se ele quiser se divertir com alguém tem que ir pra cidade (fragmento de entrevista).

Cada um tem os seus afazeres aí fica mais em casa. E dia de semana tem aula. A gente não deixa ela muito solta. Mas ela vai, volta e meia, aqui nos vizinhos de bicicleta. Tem duas gurias aqui, vizinhas. Mas no caso dela é mais na escola (fragmento de entrevista).

Muitas vezes, sem a companhia de irmãos ou vizinhos, a interação se estabelece com os animais de estimação:

Mais ela fica aqui dentro, no fim das coisas, faz a lição. Se prende às vezes com os cachorros... Brinca mais sozinha. Não tem mais ninguém aqui no pessoal vizinho (fragmento de entrevista).

O computador, por meio das redes digitais, tem se constituído, também, em um espaço de sociabilidade para os filhos dos agricultores na zona rural: "Eles também não vão se visitar mais, porque podem se falar pelo computador" (fragmento entrevista).

Para aquelas crianças que residem em localidades mais povoadas, ainda têm na vizinhança e nos centros comunitários, tais como as sociedades, espaços de experiências lúdicas com outras crianças de idades semelhantes.

Ela brinca com as amigas seguido. Toda a semana a gente vai aqui em cima na sociedade e elas vão lá e brincam. Nas quartas e sábados (fragmento de entrevista).

$\mathrm{O}$ universo de saberes e fazeres que se consolidava no cotidiano da agricultura familiar vivenciado pelos pais conformava as experiências da dimensão lúdica e que não mais se expressam no cotidiano dos seus filhos. Na formação dos pais, lúdico e trabalho mesclavam-se. Na formação dos filhos, preponderam como espaços de aprendizado e sociabilidade a escola e a casa, conformando, portanto, outras experiências lúdicas. Esses 
movimentos, ou mudanças, provocam, nos pais, sentimentos e direcionamentos ambíguos, de adequação, mas também de inconformismo, de desconsolo e de desautorização dos tradicionais papéis de educadores dos próprios filhos. Resta saber como é vivido e sentido pelas crianças tais relações, tema ainda a ser investigado.

\section{Considerações finais}

A agricultura familiar, como uma forma social de vida e de trabalho, está inserida nas relações econômicas, culturais, sociais e políticas do macro contexto social, que expressam ambiguidades e contradições próprias das determinações do capital sobre o trabalho. Os agricultores familiares de Agudo estão inseridos em processos de subordinação às agroindústrias de tabaco, que determinam tanto as condições tecnológicas e de trabalho, quanto aos preços pagos pela matéria prima da produção industrial de cigarros. Embora os agricultores familiares tenham certa consciência dos processos de subordinação agroindustrial e dos riscos que o trabalho do tabaco representa, eles precisam dar continuidade à produção a fim de obter os recursos que necessitam para garantir o sustento de suas famílias.

As condições materiais e produtivas da agricultura familiar fumageira modificaram os processos tradicionais de socialização das novas gerações, em que os adultos ensinavam a seus filhos os ofícios, para garantir a continuidade dos modos de vida. Na percepção dos pais, o trabalho das crianças tem um caráter educativo e de formação das futuras gerações. Portanto, os pais não concordam que haja exploração do trabalho infantil, uma vez que observam os limites físicos de cada filho, os riscos que certos trabalhos representam e os tempos da escola e da vivência lúdica. 
Os novos dispositivos legais também modificam os processos de socialização e as percepções de infância e do trabalho das crianças entre os agricultores familiares de Agudo, desautorizando os pais como educadores dos filhos, indicando que "lugar de criança é na escola, não no trabalho". Assim, a escola tornou-se instituição central na sociabilização das crianças, ao mesmo tempo em que exerce influência importante no futuro das mesmas, no sentido de prepará-las para outras ocupações laborais fora do trabalho do campo. Dessa forma, a escola contribui para intensificar o processo de negação do rural já na própria formação escolar.

Outras mudanças podem ser constatadas nas vivências do lúdico com o maior "consumo" de brinquedos e de jogos da indústria do entretenimento, diferente dos seus pais que produziam e consumiam os próprios brinquedos e jogos. O tempo das crianças, em geral, circunscreve-se entre a escola e a casa, sendo que uma das preocupações dos agricultores concerne à permanência dos filhos na escola e a continuidade dos estudos. A maioria dos agricultores considera o trabalho no fumo pesado, tem conhecimento sobre os perigos envolvidos no manejo com essa cultura, sobre a obrigatoriedade da escolarização e sobre os marcos legais que envolvem o trabalho infantil com a cultura fumageira. Todavia, se a agricultura familiar tem como especificidade central as relações de trabalho tecido na propriedade e pelo grupo familiar, o deslocamento do processo educativo e lúdico na escola pode levar a negação desta e, portanto, como os próprios agricultores expressam, o "fim da agricultura familiar".

Destacamos que as diferenças encontradas entre o sentido da infância dos pais agricultores, em relação aos seus filhos, circunscrevem-se em um contexto em que a 
própria materialidade da agricultura familiar e da vida no campo vêm sofrendo transformações que influenciam na vida dos sujeitos, sejam adultos ou crianças.

\section{REFERÊNCIAS}

ARIÈS, P. História social da criança e da família. Rio de Janeiro: LTC editora, 1981.

BENJAMIN, W. Reflexões: a criança, o brinquedo, a educação. São Paulo: Summus, 1984.

FALK, J.W et al. Suicídio e uso de agrotóxicos: consequência do uso de agrotóxicos organofosforados? Relatório de Pesquisa. In: RS. Relatório Azul 1995 - relatório da Comissão de Cidadania e Direitos Humanos do RS. Porto Alegre: AL, 1995. p. 142-155.

GOMES, C.L. Lúdico. In: GOMES, C. L.(Org.) Dicionário Crítico do Lazer. Belo Horizonte: Autêntica, 2004, p.141-146.

IBGE. Instituto Brasileiro de Geografia e Estatística. Pesquisa Nacional de Amostra de Domicílios - 2001. Rio de Janeiro: IBGE, 2003.

KASSOUF, A.L. O que conhecemos sobre o trabalho infantil? Revista Nova Economia, Belo Horizonte, v. 17, n.2, p. 323-350, maio/agosto de 2007.

MARCELLINO, N.C. Pedagogia da animação. Campinas: Papirus, 1990.

MARIN, J.O.B.; MARIN, E.F.B. A internacionalização dos direitos das crianças e suas repercussões na regulação jurídica e combate ao trabalho infantil no Brasil. Revista Latinoamericana de Estudios del Trabajo, v. 20, p. 129-154, 2008. Disponível em: http://www.izt.uam.mx.alast/index_archivos/page1631.htm. Acesso em: 17 jun. 2013.

MARIN, J.O.B. et al. O problema do trabalho infantil na agricultura familiar: o caso da produção de tabaco em Agudo - RS. Revista de Economia e Sociologia Rural, Piracicaba-SP, vl. 50, nº 4, p. 763-786, Out/Dez, 2012.

MARIN, J.O.B. et al.. Infância e trabalho no cultivo do tabaco no Rio Grande do Sul. CONGRESSO DA SOCIEDADE BRASILEIRA DE ECONOMIA, ADMINISTRAÇÃO E SOCIOLOGIA RURAL, 49, 2011. Anais.... Belo Horizonte, 2011.

MARX, K. O capital: crítica da economia política. Rio de Janeiro: Civilização Brasileira, 2006.

SCHNEIDER, S. O trabalho infantil no ramo agrícola brasileiro: uma apreciação do estudo da OIT. Porto Alegre: FETAG/RS; Série Documentos, 2005. 


\section{Endereço dos Autores:}

Elizara Carolina Marin

Alameda Santiago do Chile 155/402

Bairro Lourdes

Santa Maria - RS - 970505685

Endereço Eletrônico: elizaracarol@yahoo.com.br

Andressa Aita Ivo

Rua General Neto, Residencial Viena 551/301, Bairro centro,

Santa Maria - RS - 97050-241

Endereço Eletrônico: dessaaita@gmail.com

Giovani Frizzo

Andrade Neves, 1195/402, Centro

Pelotas - RS - 96020-080

Endereço Eletrônico: gfrizzo2@gmail.com

Joel Orlando Bevilaqua Marin

Alameda Santiago do Chile 155/201

Bairro Lourdes

Santa Maria - RS - 970505685

Endereço Eletrônico: bevilaquamarin@gmail.com 